\title{
Von Grafenstein Gareis, Johanna (COORD.), (2006) El Golfo-Caribe y sus puertos. TOMo I, 1600-1850, MÉxico: Instituto Mora.
}

\author{
Emiliano Gallaga-Murrieta
}

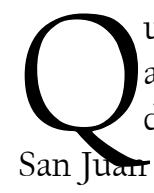

uien llega al puerto de Veracruz está obligado a tomar un café en La Parroquia, ver bailar danzón por la noche y visitar el fuerte de trang no es más que un mudo testigo de lo que sus muros y cañones representaron para la formación y el desarrollo no sólo del puerto de Veracruz, sino también de la Nueva España en general. En pleno siglo XXI, cuando no dejamos de oír hablar sobre globalización, mercados emergentes e intercambio de recursos como males de nuestra centuria, la historia nos demuestra con parcas palabras que "no existe nada nuevo bajo el sol". Ya en el México colonial se discutían los mismos conceptos, problemas y propuestas de solución. En este primer volumen de El Golfo-Caribe y sus puertos, los autores nos demuestran que la mar, en este caso la del Golfo de México y el Caribe, no es ni fue una barrera, una frontera o una limitante para el desarrollo de las comunidades localizadas en sus costas, sino todo lo contrario. Fue "un mar de oportunidades". Por ello, si usted, querido lector, está interesado en puertos, economía marítima, tráfico ilegal oceánico, afrodescendientes y su desarrollo histórico, éste es un libro de obligada lectura.
Cuenta con trece excelentes capítulos — contando la introducción de la editora -,realizados por el mismo número de investigadores de distintas nacionalidades, a quienes une el interés común por el desarrollo histórico de los puertos en la época colonial y su participación en la formación de una economía regional cuyos retos y problemáticas no demeritan en nada los contextos actuales de las economías de la región. En general, los diversos autores relatan la formación y el progreso de los distintos puertos que se crearon en esta gran área, como Curazao, Cartagena, Barbados, La Habana, Nueva Orleans, Maracaibo y Veracruz. Pero, de igual forma, recorren los fuertes que dieron su fisonomía a los puertos de estas costas, como San Juan de Ulúa, El Carmen o Cartagena de Indias. Asimismo, describen las economías regionales - capitulo 13-, los productos exportados y los recibidos, el comercio de esclavos y el tan atacado, pero tan socorrido, comercio ilegal... ilegal para algunos, pero legal para otros.

De una manera muy interesante, se retrata cómo se impulsaron los puertos mencionados, tanto los que estaban sujetos a la estructura conservadora y proteccionista de la Corona española, como aquellos que pertenecían a potencias cuyos sistemas económicos

Emiliano Gallaga-Murrieta. Universidad Autónoma de Chiapas. Profesor invitado en la Universidad de Arizona.

Recibida: 15 de julio de 2013. 
fueron más liberales. En un primer caso, se analiza el peso que tuvo la economía netamente legal contra la de contrabando para el desarrollo del puerto de Cartagena de Indias, para llegar a una interesante conclusión: aunque el contrabando fue una de las actividades más importantes para el desarrollo de la región —insumos, esclavos o instrumentos de metal- junto con el comercio legal, el puerto de Cartagena fue sostenido principalmente por la plata proveniente de Veracruz, con la que se mantenía el fuerte ahí localizado para defender la región contra los piratas y fuerzas enemigas de la Corona — capitulo 2-. Este sistema se asemeja un poco al sistema misional que implantó en el norte de México la orden de los jesuitas, donde las misiones establecidas ayudaban a las menos desarrolladas. En este caso, los virreinatos más favorecidos contribuían al sostenimiento de los más débiles. Casos similares son ejemplificados con los puertos de El Carmen y Campeche, en México, y los de Cuba en general. En el caso de El Carmen, que contaba con un puerto muy socorrido, sobre todo por el comercio del palo de tinte, la región vivía en gran manera tanto del comercio ilegal, donde participaban comerciantes y militares por igual, como de la estructura militar del Imperio español para el sostenimiento de su fuerte — capítulo 9- En el caso de Cuba, sus puertos se desarrollaron en un primer momento debido a dos factores: el desarrollo agrícola de la isla, principalmente a partir de haciendas azucareras, y la ventaja que suponía el que toda nave que llegara de España tenía que atracar primero en Cuba. Posteriormente, la presencia de piratas y de potencias extranjeras provocó la fortificación de sus puertos, como el de La Habana; estas fortificaciones fueron incorporadas al presupuesto militar de la Nueva España y así se favoreció, por tanto, su desenvolvimiento económico - capítulos 6y 7-. De esta manera, puertos creados dentro de la estructura imperial española se desarrollaron en gran medida gracias a los recursos inyectados para su defensa y para la burocracia militar, más que para favorecer el comercial legal, esto último debido principalmente a malas políticas y a reglamentos proteccionistas que fomentaron el tráfico ilegal mermando las entradas de capital.
Ocurre lo contrario en otros puertos como el de Curazao, Bridgetown o Nueva Orleans, donde políticas comerciales más liberales permitieron un rápido desarrollo económico cuyo beneficio no se destinó sólo a las potencias fundadoras, sino en cierta medida también a la Nueva España. Lo que era considerado comercio ilegal para unos, era legal para otros. Pero no sólo eso, sino que, por un lado, las autoridades de la Nueva España y de la misma España atacaban y trataban de controlar el tráfico ilegal, mientras que en la realidad también lo toleraban debido a que este tipo de comercio proporcionaba una serie de insumos que no podían llegar de otra manera a estas regiones o eran excesivamente caros.

Se describe también el caso concreto de Curazao -capítulo 3-, una isla que los holandeses tomaron a España en 1634, después de que esta potencia perdiera liderazgo en los mares debido a la derrota de la Armada Invencibleen 1588. A diferencia de España, los holandeses, así como los ingleses y franceses, crearon compañías comerciales con amplio margen de maniobra que les proporcionaran grandes rendimientos económicos. Así, contaban con la Compañía Neerlandesa de las Indias Occidentales, que pronto se estableció en Curazao, de tal manera que en poco tiempo su puerto fue un referente como puerto libre, donde incluso navíos de bandera del Imperio español llegaban a fondear. Una situación similar se desarrolló con el puerto de Bridgetown, Barbados, fundado en 1628, en esta ocasión bajo el gobierno de los ingleses - capítulo 4-. Este puerto, gracias a la producción de azúcar y a sus políticas comerciales, pronto llegó a ser conocido como la puerta de las Antillas. Un aspecto importante que resaltó de este puerto fue el de sus pobladores, de origen africano o afrodescendiente, quienes llegaron a la isla en calidad de esclavos pero que - en su mayor parte- adquirieron pronto su libertad y contribuyeron al desarrollo del puerto laborando en los innumerables servicios que éste requería.

Cuando pensamos en el Caribe colonial, pocas veces nos viene a la mente el puerto-ciudad de Nueva Orleans - capítulo 8-. Fundado en 1718 por los franceses, y posteriormente vendido a los norteamericanos 
en 1803, no tardó en llegar a ser uno de los puertos referentes de la región, impulsado principalmente por su comercio interno con las haciendas algodoneras del sur de esta nueva nación, y por su comercio exterior con los distintos puertos de la región. Con la Nueva España sostendría un gran mercado, sobre todo con los territorios del noreste, que de alguna manera tendrían una gran influencia en la separación de estos territorios. Sin embargo, lo que atrae de esta colaboración es cómo se muestra la pluriculturalidad del puerto, en el que interactuaron y se mezclaron distintas culturas y grupos, como franceses, ingleses, americanos y los esclavos negros africanos, que proporcionaron una peculiar fisonomía al lugar. Hay que mencionar que, aunque esta característica no fue exclusiva de este puerto, sí sobresale por su interacción cultural.

El caso del de Maracaibo - capítulo 5- es interesante por tratarse de un puerto que perteneció a la Corona española pero cuyo desarrollo se emparentó más con los de los puertos de las potencias no hispanas. Es decir, su posición geográfica lo convirtió en un puerto de entrada y salida de lo que hoy es Venezuela, donde sus autoridades - al igual que muchas otras - participaron abiertamente en el comercio con los puertos y navíos extranjeros, tanto para beneficio personal como de la economía regional, principalmente basada en haciendas de cacao. Y aunque el presupuesto de la burocracia militar sí participó en el desarrollo de la región, no fue tan marcado como en los otros puertos.

Aunque la mayoría de los artículos se centraron en lo económico, en algunos son presentados otros temas, como el análisis espacio-temporal que se hizo de cómo fue creciendo el puerto de Veracruz entre los siglos XVII y XIX - capitulo 10-. Gracias a la identificación de varios planos e ilustraciones sobre éste, el autor realizó un análisis de cómo las necesidades, tanto internas como externas, hicieron del puerto de Veracruz el principal puerto de la región, hasta el punto de que llegó a ser considerado la "puerta de entrada de la Nueva España".

Si algo caracterizó esta época y su comercio fue el mercado de esclavos provenientes de África — capitulo 11-. Al principio de la Colonia, los esclavos negros que llegaron formaron parte de la servidumbre de los peninsulares, pero, conforme la población local fue menguando y las necesidades de mano de obra se hicieron más patentes, se comenzó a traer negros africanos para otros trabajos. También se desarrolló un importante comercio legal de esclavos, ampliamente controlado y regulado por la Corona española, de modo que llegó a registrarse la entrada de entre doscientos y doscientos mil esclavos al Virreinato de México. Por otro lado, el tráfico ilegal de esclavos no se encuentra registrado en los archivos coloniales de la Nueva España por obvias razones, pero sí consta en los registros de otros puertos. Por ejemplo, hay registros en los archivos de la Compañía Neerlandesa de las Indias Occidentales, a la que se atribuye la introducción de un poco más de cien mil "piezas" a puertos de la Nueva España, o de la Royal African Company establecida en Bridgetown, Barbados, que participó con cincuenta y tres mil esclavos sólo entre 1705 y 1725.

De esta manera, ya sea por curiosidad o por intereses de investigación, El Golfo-Caribe y sus puertos es un libro en el que los lectores encontrarán datos sumamente interesantes. 